\title{
Liver Dysfunction due to Anti-Thyroid Drugs
}

\author{
Hidekatsu Yanai
}

\section{To the Editor}

Graves' disease is the most common cause of hyperthyroidism, which is induced by thyrotropin receptor (TSH-R) stimulation by autoantibodies [1]. Patients with overt Graves' hyperthyroidism should be treated with any of the following modalities: radioactive iodine therapy, anti-thyroid drugs (ATDs), or thyroidectomy [1]. In Europe, Latin America, and Japan, there has been a greater physician preference for ATDs [2]. In Japan, Graves' disease is usually treated by using the thionamide ATDs such as methimazole (MMI) and propylthiouracil (PTU). The adverse reactions of ATDs include fever, rash, agranulocytosis, and hepatitis. These reactions usually occur within the first few months on initiating treatment [3]. Graves' disease management guidelines of the Japanese Thyroid Association recommend that MMI should be used in every patient with Graves' disease as the first-choice drug except for during the first trimester of pregnancy. Here, I will present a case with Graves' disease whose liver dysfunction due to MMI was ameliorated by the reduction of MMI dose.

An 87-year old woman was referred to our hospital due to hyperthyroidism, and was diagnosed as having overt Graves' hyperthyroidism by the existence of anti-TSH-R antibody (5.8 IU/L; normal range, $<2.0 \mathrm{IU} / \mathrm{L}$ ). Her serum TSH, free triiodothyronine (T3), and free thyroxine (T4) levels were $<0.03 \mu \mathrm{U} /$ $\mathrm{mL}$ (normal range, $0.54-4.26 \mu \mathrm{U} / \mathrm{mL}$ ), $5.18 \mathrm{pg} / \mathrm{mL}$ (normal range, $2.39-4.06 \mathrm{pg} / \mathrm{mL}$ ) and $1.55 \mathrm{ng} / \mathrm{dL}$ (normal range, 0.71 - $1.52 \mathrm{ng} / \mathrm{dL}$ ), respectively. Daily $15 \mathrm{mg}$ of MMI promptly reduced serum free T3 and free T4 levels, however, deteriorated liver function after 4 weeks (Fig. 1). At the same time, an elevation of serum triglyceride (TG) level was observed (Fig. 1), which let me think the possibility that this liver dysfunction was led by a drastic change of metabolism accompanying normalization of thyroid function. Serum aspartate aminotransferase (AST) and alanine transaminase (ALT) levels decreased in parallel with serum TG by reducing daily dose of MMI, supporting my hypothesis.

When we observe liver dysfunction due to MMI, we are likely to switch from MMI to PTU. However, PTU is known to cause severe hepatic failure, particularly in children [4]. Further-

Manuscript submitted March 20, 2018, accepted March 30, 2018

Department of Internal Medicine, National Center for Global Health and Medicine Kohnodai Hospital, 1-7-1 Kohnodai, Ichikawa, Chiba 272-8516, Japan. Email: dyanai@hospk.ncgm.go.jp

doi: https://doi.org/10.14740/jem498w more, liver dysfunction was more frequently observed in PTU treatment than in MMI treatment [5]. Niculescu et al retrospectively analyzed 77 patients presenting with newly diagnosed overt hyperthyroidism, and suggested that MMI treatment can induce insignificant liver function tests (LFTs) elevation $(<2 \times$ the upper limit of normal range) and MMI can be safely administered in hyperthyroid patients with abnormal LFT, and normalization of increased AST and ALT levels should be anticipated [6]. However, the mechanism for normalization of liver function during MMI treatment remains largely unknown.

Since thyroid hormone plays a key role in regulating whole-body metabolism and lipid utilization by the liver, hypothyroidism has been associated with increased serum levels of TG and cholesterol as well as non-alcoholic fatty liver disease (NAFLD) [7-10].

In conclusion, decreases of serum AST and ALT levels in parallel with decrease of serum TG by reducing daily dose of MMI in my case may reflect changes of hepatic and systemic lipid metabolism due to reduction of thyroid hormone by MMI.

\section{Conflict of Interest}

The author declares that he has no conflict of interest concerning this article.

\section{References}

1. Ross DS, Burch HB, Cooper DS, Greenlee MC, Laurberg P, Maia AL, Rivkees SA, et al. 2016 American Thyroid Association Guidelines for diagnosis and management of hyperthyroidism and other causes of thyrotoxicosis. Thyroid. 2016;26(10):1343-1421.

2. Wartofsky L, Glinoer D, Solomon B, Nagataki S, Lagasse R, Nagayama Y, Izumi M. Differences and similarities in the diagnosis and treatment of Graves' disease in Europe, Japan, and the United States. Thyroid. 1991;1(2):129135.

3. Cooper DS. Antithyroid drugs. N Engl J Med. 1984;311(21):1353-1362.

4. Akmal A, Kung J. Propylthiouracil, and methimazole, and carbimazole-related hepatotoxicity. Expert Opin Drug Saf. 2014;13(10):1397-1406.

5. Werner MC, Romaldini JH, Bromberg N, Werner RS, Farah CS. Adverse effects related to thionamide drugs and their dose regimen. Am J Med Sci. 1989;297(4):216-219.

6. Niculescu DA, Dusceac R, Galoiu SA, Capatina CA, Poiana $\mathrm{C}$. Serial changes of liver function tests before and 


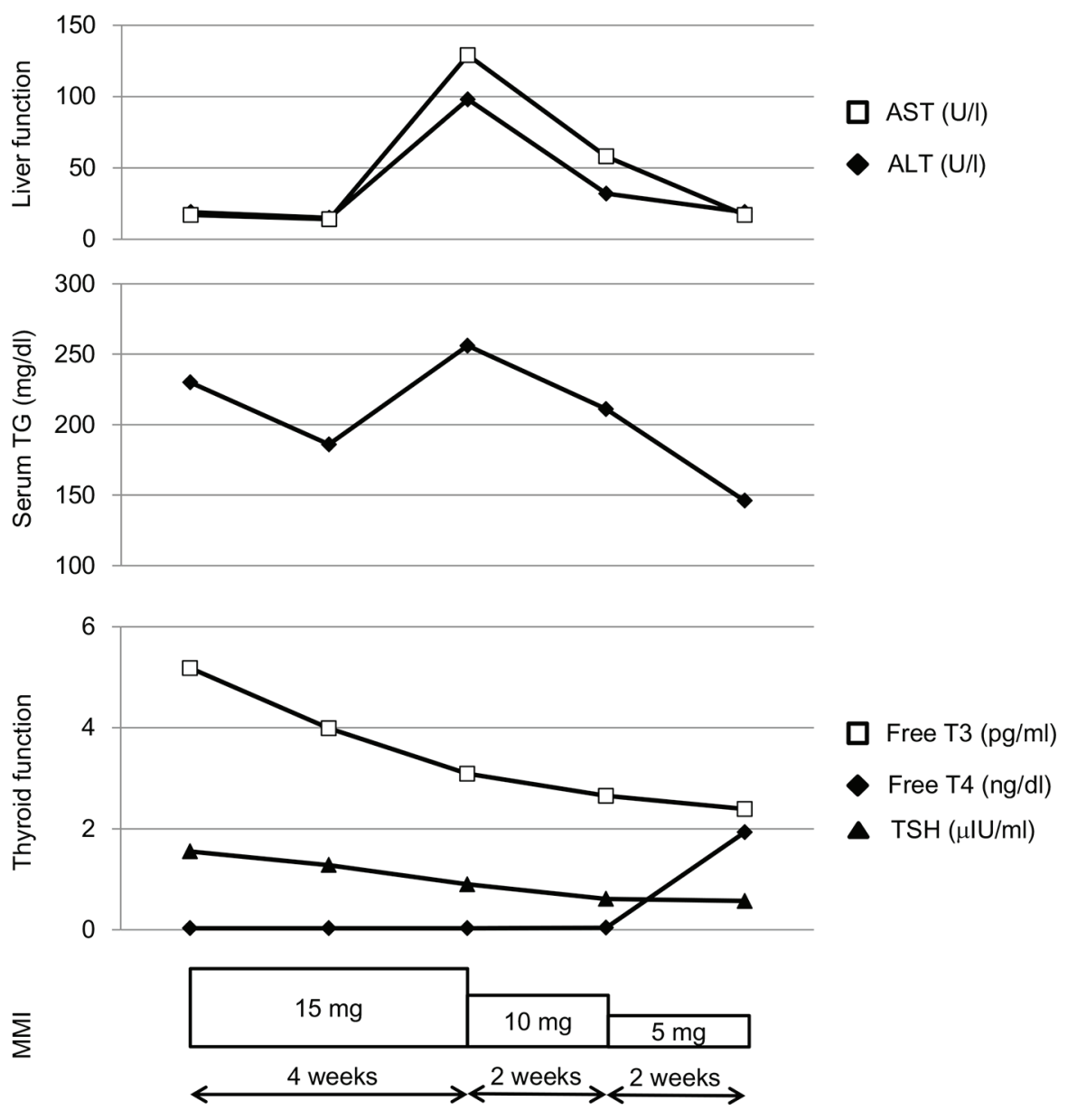

Figure 1. Changes in liver function, serum triglyceride (TG) and thyroid function during methimazole (MMI) treatment in a patient with Graves' disease.

during methimazole treatment in thyrotoxic patients. Endocr Pract. 2016;22(8):974-979.

7. Sinha RA, Singh BK, Yen PM. Direct effects of thyroid hormones on hepatic lipid metabolism. Nat Rev Endocrinol. 2018.

8. Liangpunsakul S, Chalasani N. Is hypothyroidism a risk factor for non-alcoholic steatohepatitis? J Clin Gastroenterol. 2003;37(4):340-343.
9. Pagadala MR, Zein CO, Dasarathy S, Yerian LM, Lopez $\mathrm{R}$, McCullough AJ. Prevalence of hypothyroidism in nonalcoholic fatty liver disease. Dig Dis Sci. 2012;57(2):528534.

10. Chung GE, Kim D, Kim W, Yim JY, Park MJ, Kim YJ, Yoon JH, et al. Non-alcoholic fatty liver disease across the spectrum of hypothyroidism. J Hepatol. 2012;57(1):150156. 